\title{
Development and evaluation of metronidazole loaded carbopol 934P mucoadhesive microcapsules for sustained drug release at the gastric mucosa
}

\author{
Bolai Paul, Senthil Adimoolam*, Mohd Javed Qureshi \\ Department of Dosage Form Design, Faculty of Pharmacy, MAHSA University, Selangor, Malaysia.
}

\begin{tabular}{l}
\hline ARTICLE INFO \\
\hline Received on: 07/05/2018 \\
Accepted on: 17/07/2018 \\
Available online: 30/12/2018 \\
\hline Key words: \\
Metronidazole, mucoadhesive \\
drug delivery, sustained \\
drug release, ion gelation \\
technique, ANOVA analysis.
\end{tabular}

\section{INTRODUCTION}

Metronidazole[1-(2-hydroxyethyl)-2-methyl-5-nitroim idazole] is a broad spectrum antimicrobial agent (Garud and Garud, 2010). It has the major disadvantage of short biological half-life (6-hours), bitter taste which leads to patient's non-compliance; in addition to some side effects like nausea, abdominal cramps, and metallic taste (Kumar et al., 2011). Metronidazole is sparingly soluble in water, slightly soluble in acetone and in dichloromethane, with good solubility at $\mathrm{pH} 1.2$, and the $\mathrm{pH}$ of the terminal ileum and colon is higher $(\mathrm{pH}-6.8$ and 8) (Mazumder et al., 2010; Shivangi et al., 2016). Molecular structure is shown in Figure 1.

\footnotetext{
*Corresponding Author

Senthil Adimoolam, Department of Dosage Form Design, Faculty of Pharmacy, MAHSA University, Selangor, Malaysia.

E-mail: senthil@mahsa.edu.my.
}

Mucoadhesive drug delivery systems (microcapsules) have developed to raise the contact time or residence time with mucous layer and absorption tissue of the dosage forms thereby resulting in improving drug absorption, increase bioavailability, and also work in sustained release of drugs which are influenced to reduce the gastric motility time and diminish peak plasma fluctuations (Kumar et al., 2013; Reddy et al., 2017). It is a great part of novel drug delivery and gastro-retentive drug delivery system. It is also called bioadhesive system leading to a drug administration frequency decrease, helping to retain a valuable concentration of the drug at the site of action, and an improvement in patient's compliance (Carvalho et al., 2010). Gastroretentive drug delivery system is a novel pathway in pharmaceutical products. The systems are provided to retains the dosage forms in the gastrointestinal tract for a prolonged period of times before it reaches its absorption site, slowly release the drug and longtime of retention in the stomach, consequently increase bioavailability, reduce drug wastage, and also drugs are highly soluble at less $\mathrm{pH}$ condition but drugs are less soluble at high $\mathrm{pH}$ condition. 
They are also attained local delivery of drugs to the gastrointestinal tract and proximal small intestine and prolonged gastric residence time (Rizwana et al., 2013; Uttam et al., 2016). It is able to extend the duration of drug release in the stomach, and short half-lives are quickly eliminated from systemic circulation (Badoni et al., 2012).

Sustained release dosage forms are being developed to obtain a longer therapeutic activity by slowly releasing the drug over an extended period of time at a constant rate after single administration (Bhargava et al., 2013). It has been reported that sustained release drug delivery system could overcome the several problems of conventional dosage forms, including patient incompliance, frequent administration, fluctuation in steady state drug level, etc. Sustained release dosage form have also reduced the long-term cost of healthcare through improved therapy and reduced treatment period (Arjun et al., 2012; Kube et al., 2015). Nowadays, sustained release dosage form has gained a tremendous development with the invention of new functionalized innovated polymers in order to prolong the release and target the drug at a specific site or organ (Bhatt et al., 2015; Satinder et al., 2012). The aim of this study was to develop a mucoadhesive drug delivery system of metronidazole by ion gelation method using polymer sodium alginate and carbopol 934P as cross-linked calcium chloride to incorporated mucoadhesive microcapsules.

\section{MATERIALS AND METHODS}

\section{Materials}

Metronidazole was purchased from Sigma-Aldrich Company, Germany. Sodium alginate, carbopol 934P, and calcium chloride were obtained as a gift sample from MAHSA University, Malaysia.

\section{Formulation of metronidazole mucoadhesive microcapsules}

Formulation of metronidazole mucoadhesive microcapsules was formulated by using ion gelation technique (Hosmani et al., 2009). Sodium alginate-carbopol 934P as mucoadhesive polymers was dissolved in 10-ml purified water to form a homogeneous polymer solution. The metronidazole active ingredients were added to the polymeric solution and mixed thoroughly with a stirrer to form a viscous dispersion. The resulting dispersion solution was added manually dropwise into $10 \% \mathrm{w} / \mathrm{v}$ calcium chloride solution $(40 \mathrm{ml})$ through a syringe (no. 21). The

Table 1. Metronidazole mucoadhesive microcapsules by carbopol 934P with their experimental coded level of variables for $3^{2}$ factorial designs

\begin{tabular}{ccc}
\hline Formulation code & \multicolumn{2}{c}{ Variable levels in coded form } \\
\hline Metronidazole (250 mg) & $\begin{array}{c}\boldsymbol{X}_{\mathbf{1}} \text { (concentration of } \\
\text { sodium alginate) }\end{array}$ & $\begin{array}{c}\boldsymbol{X}_{\mathbf{2}} \text { (concentration of } \\
\text { carbopol 934P) }\end{array}$ \\
\hline F1 & -1 & -1 \\
F2 & -1 & 0 \\
F3 & -1 & +1 \\
F4 & 0 & -1 \\
F5 & 0 & 0 \\
F6 & 0 & +1 \\
F7 & +1 & -1 \\
F8 & +1 & 0 \\
F9 & +1 & +1 \\
\hline
\end{tabular}

added droplets were retained in the calcium chloride solution for 1 hour to complete the reaction and to produce spherical rigid mucoadhesive microcapsules. The mucoadhesive microcapsules were collected by decantation and the products were separately washed frequently and dried at $40^{\circ} \mathrm{C}$ for 3 hours in a hot air oven.

\section{$3^{2}$ factorial designs}

A response surface method $3^{2}$ factorial designs were applied to evaluate the relationship between the independent variables and their responses. Two variables and six responses were involved in the experimental design. The dependent response factor variables measured were percentage yield, \% entrapment efficiency, particle size, swelling index (SI), percentage mucoadhesion, and drug release. The independent variables are the concentration of sodium alginate $\left(X_{1}\right)$ and the concentration of polymer carbopol 934P $\left(X_{2}\right)$ was classified as low, medium, and high and their value was shown in Table 2 (Hosmani et al., 2009).

Various formulations of metronidazole-carbopol 934P mucoadhesive microcapsules were prepared individually by using all combinations of different levels of experimental variables as shown in Table 1.

\section{Evaluation of metronidazole mucoadhesive microcapsules}

\section{Fourier transform infrared spectroscopy (FT-IR)}

FT-IR is a rapid, easy, and inexpensive analytical technique that is used to predict drug-excipient interactions. This analysis was performed by using the potassium bromide pellet method. FT-IR of metronidazole and metronidazole with individual polymers was taken, weighed, and mixed homogenously with $300 \mathrm{mg}$ of potassium bromide. After that, the mixture was compacted into a translucent film by using mechanical die press. It was recorded on Shimadzu's Fourier transform infrared spectrometer (Japan) with a frequency range of 4,000-450 $\mathrm{cm}^{-1}$ (Emara et al., 2014; Shastri et al., 2016).

\section{Particle size measurement}

Metronidazole mucoadhesive microcapsules of particle size were evaluated by using optical microscopy method. The amount was done under $10 \times 45(10 \times$ eyepiece and $45 \times$ objective $)$ and 100 mucoadhesive microcapsules counted for particle size analysis by using a calibrated optical microscope. First of all, 100 mucoadhesive microcapsules were taken and kept in a glass slide. It was mixed with glycerin and set in an optical microscope, then determined the particle size (Shankar et al., 2011).

\section{Percentage yield}

Percentage yield of metronidazole mucoadhesive microcapsules was calculated to know the efficiency of the methods used during the preparation, which might be useful in the

Table 2. Translation of coded levels of metronidazole mucoadhesive microcapsules by carbopol $934 \mathrm{P}$ in actual units.

\begin{tabular}{ccc}
\hline & Metronidazole (250 mg) \\
\hline & $X_{1}=$ Concentration of sodium alginate $(\% \mathrm{w} / \mathrm{v})$ \\
Low $125 \mathrm{mg}(-1)$ & Medium $187.5 \mathrm{mg}(0) \quad$ High $250 \mathrm{mg}(+1)$ \\
& $X_{2}=$ Concentration of carbopol 934P $(\% \mathrm{w} / \mathrm{v})$ \\
Low $250 \mathrm{mg}(-1)$ & Medium $375 \mathrm{mg}(0)$ & High $500 \mathrm{mg}(+1)$ \\
\hline
\end{tabular}


selection of an appropriate method for future production. Percentage yield was calculated as the weight of mucoadhesive microcapsules recovered from each formulation in relation to the sum of starting material. The percentage yield of prepared mucoadhesive microcapsules was determined by using the formula, respectively (Shwetha et al., 2012; Yadav et al., 2009).

$$
\text { Percentage yield }=\frac{\text { weight of mucoadhesive microcapsule }}{\text { Theoretical weight of polymer and drug }} \times 100
$$

\section{Drug entrapment efficiency}

One hundred milligrams of metronidazole mucoadhesive microcapsule was crushed individually in a glass mortar and pestle, and the powdered microcapsule was suspended in $10 \mathrm{ml}$ of phosphate buffer solution ( $\mathrm{pH} 7.4$ ), respectively. After 24 hours, the solution filtered and the filtrate was analyzed for the drug entrapment efficiency after it was calculated using the following formula (Hosmani et al., 2009).

$$
\frac{\text { Practical drug content }}{\text { Theoretical drug content }} \times 100
$$

\section{Swelling index (SI)}

The metronidazole mucoadhesive microcapsule $(100 \mathrm{mg})$ was placed separately in a glass vial containing $10 \mathrm{ml}$ of $0.1 \mathrm{~N} \mathrm{HCl}$ at $37^{\circ} \mathrm{C} \pm 0.5^{\circ} \mathrm{C}$ in an incubator with occasional shaking. The swelled metronidazole mucoadhesive microcapsules were removed at a predetermined time interval and weighed after drying the surface by using tissue paper. A weight of the swollen microcapsules was recorded after a period of 8 hours and swelling ratio was calculated using the following formula:

$$
\text { Percentage SI }=\left\lfloor\frac{\mathrm{Wt}-\mathrm{Wo}}{\mathrm{Wo}}\right\rfloor \times 100
$$

Whereas $\mathrm{Wt}=$ Equilibrium weight of microcapsules after swelling and $\mathrm{Wo}_{\mathrm{N}}$ Initial weight of microcapsules (Jain et al., 2007; Nagda et al., 2008).

\section{Mucoadhesion testing by in vitro wash-off test}

The mucoadhesive property of the metronidazole mucoadhesive microcapsule was evaluated by an in vitro wash-off test using goat stomach mucosa. A piece of goat stomach mucosa $(2 \mathrm{~cm} \times 2 \mathrm{~cm})$ was collected and tied onto a glass slide $(7.5 \mathrm{~cm} \times 2.5 \mathrm{~cm})$ using a thread. One hundred metronidazole mucoadhesive microcapsules were separately placed onto wet tissue specimen and the prepared slide was hung into the groove of disintegration tester. The tissue specimen was given a regularly up and down movement in a beaker containing $900 \mathrm{ml}$ of $0.1 \mathrm{~N} \mathrm{HCl}$ $(\mathrm{pH} 1.2)$ separately at $370.5^{\circ} \mathrm{C}$. At the end of the time interval, the number of mucoadhesive microcapsules that remained attached to the tissue was recorded (Nimisha and Bhattacharya, 2008; Stephen et al., 2010).

The mucoadhesion adhesion number was determined by the following formula:

$$
N_{\mathrm{n}}=\left(\frac{N}{N_{0}}\right) \times 100
$$

Where $N_{\mathrm{n}}=$ Adhesion number, $N=$ Number of mucoadhesive microcapsules attached to the mucosa after washing, and $N_{0}=$ Initial number of mucoadhesive microcapsules in the intestinal mucosa.

\section{In vitro dissolution studies}

Dissolution studies of metronidazole mucoadhesive microcapsule, equivalent to $250 \mathrm{mg}$ of metronidazole individually, were carried out by United States Pharmacopeia dissolution test apparatus (Electrolab India) at $50 \mathrm{rpm}$ and $37^{\circ} \mathrm{C} \pm 0.5^{\circ} \mathrm{C}$, using 900 $\mathrm{ml}$ of $0.1 \mathrm{~N} \mathrm{HCl}(\mathrm{pH} \mathrm{1.2)}$ as the dissolution medium. An aliquot of sample $(5 \mathrm{ml})$ was withdrawn periodically, replaced with an equivalent volume of dissolution medium. Samples, filtered through Whatman filter paper $(0.45 \mu \mathrm{m})$, was analyzed spectrophotometrically at 277 $\mathrm{nm}$. Drug release data obtained during in vitro dissolution studies were analyzed for release kinetics using zero order, first order, and Higuchi model equations and fitted into Korsmeyer-Peppas model for evaluation of release mechanism from mucoadhesive microcapsules (Badhan et al., 2009; Jiménez et al., 1994).

\section{Drug release kinetic profile}

To study the drug release kinetics and mechanism of metronidazole mucoadhesive microcapsule, the in vitro data was evaluated to find a suitable mathematical model to fit the in vitro release behavior. The following mathematical models evaluated to determine the drug release per unit time, namely zero order and first order, whereas Higuchi and Korsmeyer-Peppas models were used to evaluate the mechanism of drug release (Nayak et al., 2013).

\section{Zero order}

The zero-order equation describes in which the drug release rate is independent of its concentration of dissolved substances. The equation of zero-order release is given as follows:

$$
Q_{t}=Q_{0}+K_{0} t
$$

Where $Q_{t}=$ cumulative amount of drug release a time " $t$ ", $Q_{0}=$ initial amount of drug, $K_{0}=$ zero-order release constant, and $t=$ time in hours.

$$
\begin{aligned}
C & =k_{0} t \\
k_{0} & =\text { rate constant and concentration release is directly }
\end{aligned}
$$
proportional to time.

\section{First order}

First-order kinetic is described as absorption and/or clearance of the drug. The release rate of the drug is dependent on concentration.

$$
\log C_{t}=\frac{\log C o-k t}{2.303}
$$

Where $C=$ initial concentration of drugs and indicates first-order reaction constant.

\section{Higuchi's model}

Higuchi's model determines the kinetic profile of different geometric and porous drug delivery system. It obeys Fick's law and is square root time dependent. 


$$
Q=K_{H} t^{1 / 2}
$$

Where $K_{\mathrm{H}}=$ Higuchi dissolution constant to identify the diffusion controlled process. Drug release that calculated in time per unit area is plotted against a square of time.

\section{Korsmeyer-Peppas model}

Determine drug release mechanism of particular dosage form either by Fickian or non-Fickian.

$$
\log \left(\frac{M_{t}}{M \infty}\right)=\log k+n \log t
$$

Where $M / M \infty=$ drug release at time $t, n=$ exponent indicative of release mechanism manipulated by the polymer, and $k=$ kinetic constant with structural and geometric properties of a dosage.

\section{$3^{2}$ full factorial design studies}

A statistical model incorporating interactive and polynomial terms was utilized to evaluate the responses.

$$
Y=b_{0}+b_{1} X_{1}+b_{2} X_{2}+b_{12} X_{1} X_{2}+b_{11} X_{1}^{2}+b_{22} X_{2}^{2}
$$

Where $Y$ is the dependent variable, $b_{0}$ is the arithmetic mean response of the nine runs, and $b_{1}$ is the estimated coefficient for the factor $X_{1}$. The main effects $\left(X_{1}\right.$ and $\left.X_{2}\right)$ represent the average result of changing one factor at a time from its low-to-high value.

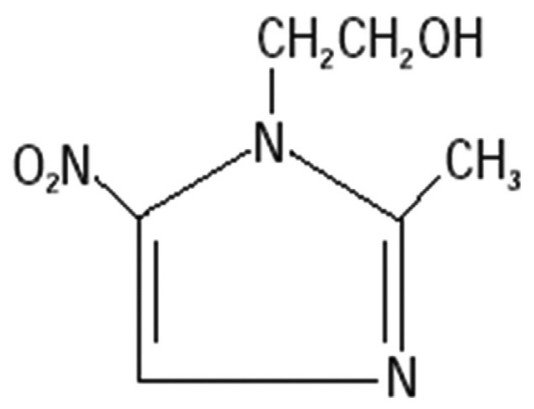

Figure 1. Molecular formula of metronidazole (Kalita et al., 2017).
The polynomial terms $\left(X_{1}^{2}\right.$ and $\left.X_{2}^{2}\right)$ are included to investigate nonlinearity.

On the basis of the preliminary trials, a $3^{2}$ full factorial design was employed to study the effect of independent variables, $X_{1}$ - concentration of sodium alginate $(\% \mathrm{w} / \mathrm{v})$, and $X_{2}$ - concentration of polymer $(\% \mathrm{w} / \mathrm{v})$ on dependent variables, particle size, $\%$ drug entrapment efficiency, SI, drug release, and percentage mucoadhesion. Factorial designs can screen for important drugs and drug interactions, as well as determine potential optimal drug dosages. Enable to build statistical models with a small number of runs. A statistical model was incorporating by using Design-Expert ${ }^{\circledR}$ Software Version 11.0.0 (Ardenia and Gupta, 2016; Hosmani et al., 2009).

\section{Statistical analysis}

Factorial equation and analysis of variance (ANOVA) analysis were used for statistical analysis. Responses observed for each of the formulations (F1-F9) were simultaneously fitted to quadratic model using Design-Expert ${ }^{\circledR}$ Software Version 11.0.0.

\section{RESULTS AND DISCUSSION}

\section{Fourier Transform Infrared Spectroscopy (FT-IR)}

FT-IR spectroscopy studies were performed to ensure that the processing time has not led to any interaction between the drug and polymer in the formulation. The FT-IR spectrum of the pure metronidazole, sodium alginate, and carbopol 934P are shown in Figure 2. Furthermore, the spectrum of carbopol 934P-sodium alginate mucoadhesive microcapsules containing metronidazole is shown in Figure 5. It was recorded on Shimadzu's Fourier transform infrared spectrometer (Japan) with a frequency range of $4,000-450 \mathrm{~cm}^{-1}$.

The sample of pure metronidazole showed feature vibrations peaks for $\mathrm{O}-\mathrm{H}, \mathrm{C}-\mathrm{H}$, and $\mathrm{C}=\mathrm{O}$ stretching frequency at $3,209.36,3,100.14$, and $1,739.19 \mathrm{~cm}^{-1}$, respectively. The peaks at around $1,471.91$ and $1,354 \mathrm{~cm}^{-1}$ are attributed to symmetric and asymmetric stretching $\mathrm{N}=\mathrm{O}$, respectively. The band peaks at $1,427.33,1,264.51-1,185.80$, and $1,073.40 \mathrm{~cm}^{-1}$ are assigned to $\mathrm{C}-\mathrm{C}$ stretching, C-O stretching, and C-N stretching, respectively. The FT-IR value of metronidazole was found to be similar as

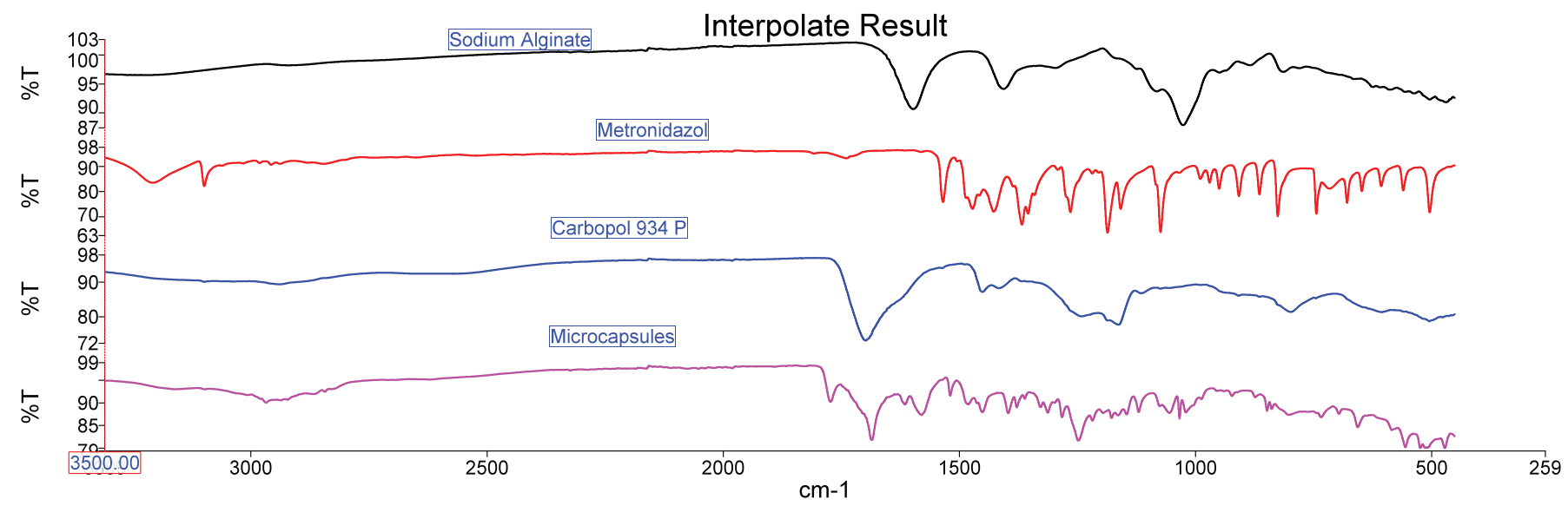

Figure 2. FT-IR spectrum of sodium alginate, metronidazole, carbopol 934P, and microcapsules. 
reported by Nnabuike et al. (2017). The FT-IR spectrum of sodium alginate has shown the peaks at about 3,228.00, 1,595.00, 1,406.95, and $1,024.32 \mathrm{~cm}^{-1}$ that are indicating of $\mathrm{O}-\mathrm{H}$ stretching vibrations, COO- stretching vibrations, $-\mathrm{CH}$ stretching vibrations, and $\mathrm{C}-\mathrm{O}-\mathrm{C}$ stretching vibrations, respectively. The FT-IR sodium alginate result was almost similar to the finding reported by (Daemi and Barikani, 2012). The FT-IR spectrum of carbopol 934P showed the band at around 2,940.81, 1,698.01, 1,450.88, and 1,162.12 $\mathrm{cm}^{-1}$, which are a result of the stretching of $\mathrm{O}-\mathrm{H}$, stretching of $\mathrm{C}=\mathrm{O}$, stretching of $-\mathrm{CH} 2$, and bending of $\mathrm{C}-\mathrm{H}$, respectively. Carbopol 934P FT-IR was found to be similar to the result reported by Subhashree et al. (2011). The FT-IR spectrum for carbopol 934P_-sodium alginate mucoadhesive microcapsules containing metronidazole showed different absorption characteristics of peaks of metronidazole, sodium alginate, and carbopol 934P were found that the almost same primary peaks were also present in the drug-polymer combinations, indicating there is no interaction between polymer and drug used as shown in Figure 2.

\section{Particle size measurement of metronidazole mucoadhesive} microcapsules

The particle size of metronidazole-carbopol 934P mucoadhesive microcapsules was showed from $765.06 \pm 0.01 \mu \mathrm{m}$ to $845.40 \pm 0.02 \mu \mathrm{m}$, respectively. Researchers have suggested that as polymer concentration increases, the particle size also improves, which could be due to increase in the viscosity of drug and polymer ratio and coat thickness of polymer (Chandra et al., 2010; Swetha et al., 2013). The current study indicated that higher concentration of sodium alginate with carbopol 934P solution was observed to more viscous result in the polymer solution was formed into large droplets and raises particle size than those of lower concentration polymers with less viscosity and therefore small droplets and diminish particle size as shown in Table 3. So, metronidazole mucoadhesive microcapsules of particle size were significantly affected by the viscosity of the polymer solution. The smallest particle size was produced when sodium alginate, carbopol 934P were used at a low-level concentration. The highest particle size was achieved when polymer concentration was acquired at a higher level.

\section{Percentage yield of metronidazole mucoadhesive microcapsules}

Metronidazole mucoadhesive microcapsules have shown that the percentage yield was in a range of $86.40 \% \pm$ $0.02 \%$ to $97.80 \% \pm 0.02 \%$, respectively. It was found that in most formulations when the polymer ratio of the formulation increases, the percentage yield was observed to increase as well. In recent studies have proved that the percentage yield of mucoadhesive microcapsules was improved within increasing concentration of sodium alginate also (Altafbhai et al., 2014). The studies have reported that the percentage yield decreased with increased sodium alginate due to the high viscosity of the drug-polymer solution, needle blockage wastage of the drug-polymer solution, loss transferring, and washing (Sathali and Varun, 2012).

\section{Drug entrapment efficiency of metronidazole mucoadhesive microcapsules}

The entrapment efficiency is a vital parameter that assists in the identification of drug efficacy and it depends on various concentrations of mucoadhesive polymers such as sodium alginate and carbopol 934P. The average efficiency ranges for metronidazole-carbopol 934P mucoadhesive microcapsules were $80.77 \% \pm 0.04 \%$ to $87.74 \% \pm 0.01 \%$, respectively, as shown in Table 3. It was observed that the drug entrapment efficiency depends on polymer concentration (sodium alginate and carbopol 934P). In present research work was shown that same sodium alginate

Table 3. Particle size, percentage yield, drug entrapment efficiency, SI, mucoadhesion, and drug release of metronidazole mucoadhesive microcapsules.

\begin{tabular}{|c|c|c|c|}
\hline Formulation code & Particle size $(\mu \mathrm{m})$ & Percentage yield $(\%)$ & Entrapment efficiency (\%) \\
\hline F1 & $765.06 \pm 0.01$ & $86.40 \pm 0.02$ & $80.77 \pm 0.04$ \\
\hline F2 & $815.00 \pm 0.08$ & $84.44 \pm 0.03$ & $82.76 \pm 0.03$ \\
\hline F3 & $828.02 \pm 0.02$ & $88.06 \pm 0.06$ & $84.75 \pm 0.01$ \\
\hline F4 & $820.04 \pm 0.05$ & $86.89 \pm 0.01$ & $83.75 \pm 0.02$ \\
\hline F5 & $850.11 \pm 0.01$ & $96.43 \pm 0.01$ & $85.75 \pm 0.04$ \\
\hline F6 & $836.09 \pm 0.03$ & $97.80 \pm 0.02$ & $87.74 \pm 0.01$ \\
\hline F7 & $842.02 \pm 0.04$ & $96.89 \pm 0.03$ & $85.06 \pm 0.03$ \\
\hline F8 & $840.03 \pm 0.05$ & $95.25 \pm 0.07$ & $86.08 \pm 0.02$ \\
\hline F9 & $845.40 \pm 0.02$ & $93.33 \pm 0.04$ & $83.73 \pm 0.05$ \\
\hline Formulation code & SI $\%$ & $\%$ Mucoadhesion & $\%$ Cumulative drug release \\
\hline F1 & $85.71 \pm 0.01$ & $47.00 \pm 0.04$ & $80.10 \pm 0.02$ \\
\hline F2 & $94.50 \pm 0.04$ & $55.00 \pm 0.02$ & $73.90 \pm 0.03$ \\
\hline F3 & $98.04 \pm 0.03$ & $61.00 \pm 0.03$ & $59.20 \pm 0.05$ \\
\hline F4 & $92.06 \pm 0.02$ & $52.00 \pm 0.05$ & $77.20 \pm 0.06$ \\
\hline F5 & $95.07 \pm 0.03$ & $60.00 \pm 0.03$ & $68.80 \pm 0.01$ \\
\hline F6 & $99.30 \pm 0.04$ & $63.00 \pm 0.07$ & $55.90 \pm 0.05$ \\
\hline F7 & $96.89 \pm 0.05$ & $58.00 \pm 0.02$ & $74.60 \pm 0.02$ \\
\hline F8 & $100.25 \pm 0.01$ & $62.00 \pm 0.04$ & $62.00 \pm 0.03$ \\
\hline F9 & $102.33 \pm 0.03$ & $64.00 \pm 0.01$ & $52.30 \pm 0.01$ \\
\hline
\end{tabular}


concentration and carbopol 934P concentration have increased the drug entrapment efficiency, as well as when sodium alginate concentration was increased, drug entrapment was also improved. In this case, the lower level of polymer concentration entrapment efficiency was lower than a higher level of polymer concentration.

On other hands, metronidazole mucoadhesive microcapsules some formulations have lower entrapment efficiency due to a decrease in the number of binding sites of alginate for $\mathrm{Ca}^{2+}$ ions, consequently formulations are less compact gel membrane which, in turn, the superior influx of $\mathrm{Ca}^{2+}$ ions leading to decrease in drug entrapment efficiency and also lower polymer concentration. Contrary, metronidazole mucoadhesive microcapsules have the highest entrapment efficiency due to increase polymer concentration, especially higher sodium alginate concentration that was formed to increase the number of binding sites of sodium alginate with calcium chloride. At polymer concentration sodium alginate $(250 \mathrm{mg})$, and carbopol 934P (500 $\mathrm{mg}$ ), the percentage of metronidazole mucoadhesive microcapsules entrapment efficiency was determined to be increased, as shown in Table 3. The result shows that the entrapment efficiency of mucoadhesive microcapsule was increased with increased polymer concentration; the result was similar to study as reported by (Anuranjita et al., 2012; Shanthi et al., 2015).

\section{Swelling index of metronidazole mucoadhesive microcapsules}

The swelling patterns of metronidazole-carbopol 934P mucoadhesive microcapsules were within the range of $85.71 \% \pm$ $0.01 \%$ to $102.33 \% \pm 0.03 \%$, respectively, as shown in Table 3 . The SI of sodium alginate and carbopol 934P loaded metronidazole mucoadhesive microcapsules varied from $85.71 \% \pm 0.01 \%$ to $98.04 \% \pm 0.03 \%$ and $96.89 \% \pm 0.05 \%$ to $102.33 \% \pm 0.03 \%$ at lower and higher levels of polymer to drug ratio, respectively, with lower and higher sodium alginate ratio were used for lower and higher levels of carbopol 934P polymer concentration. But a medium level of carbopol 934P to drug ratio, as sodium alginate gradually increased, SI was also observed an increase from $98.04 \% \pm 0.04 \%$ to $100.25 \% \pm 0.01 \%$. Therefore, metronidazole mucoadhesive microcapsules indicated that SI increased with increased polymer concentration due to increased viscosity in the formulation.

From the evaluation of metronidazole mucoadhesive microcapsules formulations, F1 to F9 is observed that formulation F9 has the highest SI due to maximum polymer concentration. The SI of all the formulations was reported to be improved with the concentration of polymers. The SI depends on the solubility of drug and polymer that could have influenced the swelling behavior of the mucoadhesive microcapsules. The result shows that the maximum SI was achieved when polymer concentration was increased; similar finding results were also observed in previous studies (Atishkumar and Pund, 2017).

\section{Mucoadhesion testing by in vitro wash-off test}

The study of in vitro bioadhesion demonstrated that metronidazole-carbopol 934P mucoadhesive microcapsules had a good bioadhesive property ranging from $47.00 \% \pm 0.04 \%$ to $64.00 \% \pm 0.01 \%$, respectively, as shown in Table 3 . These studies found that metronidazole mucoadhesive microcapsules formulation F9 for carbopol 934P had highest bioadhesive property and remained long time adhered to the stomach due to increasing mucoadhesive polymer concentration, the mucoadhesion of the microcapsules was also increased as shown in Figure 3. It was observed that mucoadhesion of metronidazole mucoadhesive microcapsules significantly increased with increasing polymer concentration due to increase in viscosity and produce stronger mucus gel network which helps to enhance mucoadhesion.

The mucoadhesion of sodium alginate-carbopol 934P loaded metronidazole mucoadhesive microcapsules varied from $47.00 \% \pm 0.04 \%$ to $61.00 \% \pm 0.03 \%$ and $58.00 \% \pm 0.02 \%$ to $64.00 \% \pm 0.01 \%$ at lower and higher levels of polymer to drug ratio, respectively, with lower and higher sodium alginate ratio were used for lower and higher levels of carbopol 934P polymer concentration. But a medium level of carbopol 934P to drug ratio, as sodium alginate gradually increased, drug entrapment efficiency was also observed an increase from $61.00 \% \pm 0.01 \%$ to $63.00 \% \pm 0.07 \%$. Therefore, metronidazole mucoadhesive microcapsules were observed that mucoadhesion was higher when polymer concentration was achieved higher levels due to higher level formulations have more viscosity. Similarly, Nagda et al. (2008) also reported that as polymer concentration was increased, it leads to increased mucoadhesion and percentage mucoadhesion was lower than present work after 8 hours.

\section{In vitro dissolution studies of metronidazole mucoadhesive microcapsules}

The present study showed that metronidazole mucoadhesive microcapsules in most of the formulations have negligible amounts of drug release in simulated gastric fluid $(0.1 \mathrm{~N} \mathrm{HCl}, \mathrm{pH} 1.2)$; whereas for those formulations were increased amount of drug release in simulated intestinal fluid ( $\mathrm{pH}$ 7.4). It was found that the percentage of cumulative drug release (CDR \%) in the range of $80.10 \% \pm 0.02 \%$ to $52.30 \pm 0.01 \%$ for metronidazolecarbopol 934P mucoadhesive microcapsules over 8 hours. The drug release profile of different formulations of sustained release metronidazole-carbopol 934P mucoadhesive microcapsules is shown in Figure 4.

The drug release of sodium alginate and carbopol 934P loaded metronidazole mucoadhesive microcapsules varied from $80.10 \% \pm 0.02 \%$ to $59.20 \% \pm 0.05 \%$ and $74.60 \%$ $\pm 0.02 \%$ to $52.30 \% \pm 0.01 \%$ at lower and higher levels of polymer to drug ratio, respectively, with lower and higher

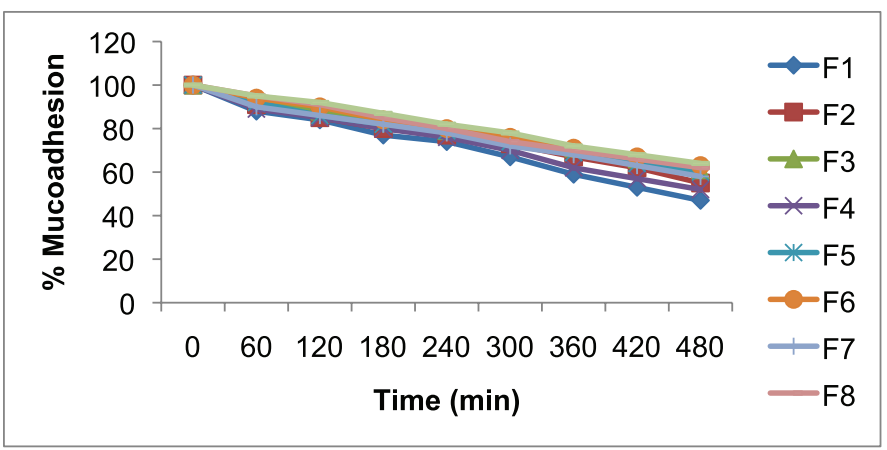

Figure 3. Mucoadhesion of metronidazole-carbopol 934P mucoadhesive microcapsules. 
sodium alginate ratio were used for lower and higher levels of carbopol 934P polymer concentration. Therefore, metronidazole mucoadhesive microcapsules were observed that drug release was lower when polymer concentration was achieved higher levels due to more viscosity of the drug and polymer solution. The present result of metronidazole mucoadhesive microcapsules was observed that the low-level polymer concentrations were failed to retard drug release $(50 \%-60 \%)$. But high-level polymer concentrations were given good retardation of drug release $(50 \%-60 \%)$ for an extended period of time. Metronidazole mucoadhesive microcapsules formulations F1 to F9 were seen that as the concentration of polymers increases, the drug release decreases.

Metronidazole mucoadhesive microcapsules formulations $\mathrm{F}$ 1 to $\mathrm{F} 9$ were observed that formulation $\mathrm{F} 9$ was the lowest drug release due to the maximum polymer concentration. It was observed that the mucoadhesive microcapsules were slow and spread over an extended period of time when sodium alginate concentration was increased; similar reported by (Abass and Kanel, 2014; Rajesh et al., 2012; Sriram and Katakam, 2016).

\section{Drug release kinetic profile}

Metronidazole-carbopol 934P mucoadhesive microcapsules F9 was selected as the most potential for its drug release kinetics model like zero order, first order, Higuchi, and Korsmeyer-Peppas models. The result of the curve fitting into various mathematical models was shown in Table 4 and Figures 7-11. The suitability of the model has been observed on the basis of best fit to the model using the correlation coefficient value $\left(R^{2}\right)$. The zero order, first order, Higuchi, and Korsmeyer-Peppas models were shown in Figures 5-8. The Korsmeyer-Peppas model was used in the in vitro release behavior evaluation of the formulations to distinguish between completing release mechanisms: Fickian release (diffusion-controlled release), non-Fickian release (anomalous transport), and case-II transport (relaxation-controlled release). When $n$ is $\leq 0.43$, it is Fickian release. The $n$ value between 0.43 and 0.85 is defined a non-Fickian release. When $n$ value is $\geq 0.85$, it is case-II transport (Pal and Nayak, 2011).

From the results shown in Table 4, it can be observed that the release kinetics of metronidazole mucoadhesive microcapsules from different formulations showed good fitting with zero order, first order, and Higuchi models with $R^{2}$ values $0.985,0.977$, and 0.858 , respectively. On the other hand, the model with the highest correlation coefficients $\left(R^{2}\right)$ was given by zero order. The $n$ value of Peppas model (0.686) indicates that the mechanism of drug release follows non-Fickian diffusion.

\section{Statistical analysis}

Quantitative results were expressed as mean \pm SD. The statistical differences were analyzed by ANOVA analysis, factorial analysis, and $p$-values $<0.05$ were considered significant. Responses observed for each of the formulations (F1-F9) were simultaneously fitted to quadratic model using Design-Expert ${ }^{\circledR}$ Software Version 11.0.0.

Statistical analysis was analyzed according to Table 3.

\section{Factorial equation}

The result of equation $Y$ that are indicated particle size, drug entrapment efficiency, SI, mucoadhesion, and drug release for all batches (F1-F9) showed a wide variation of independent and dependent variables.

The factorial equation for particle size, drug entrapment efficiency, SI, mucoadhesion, and drug release in metronidazole mucoadhesive microcapsules carbopol 934P was shown in Equations 1, 2, 3, 4, and 5. A positive co-efficient represents a

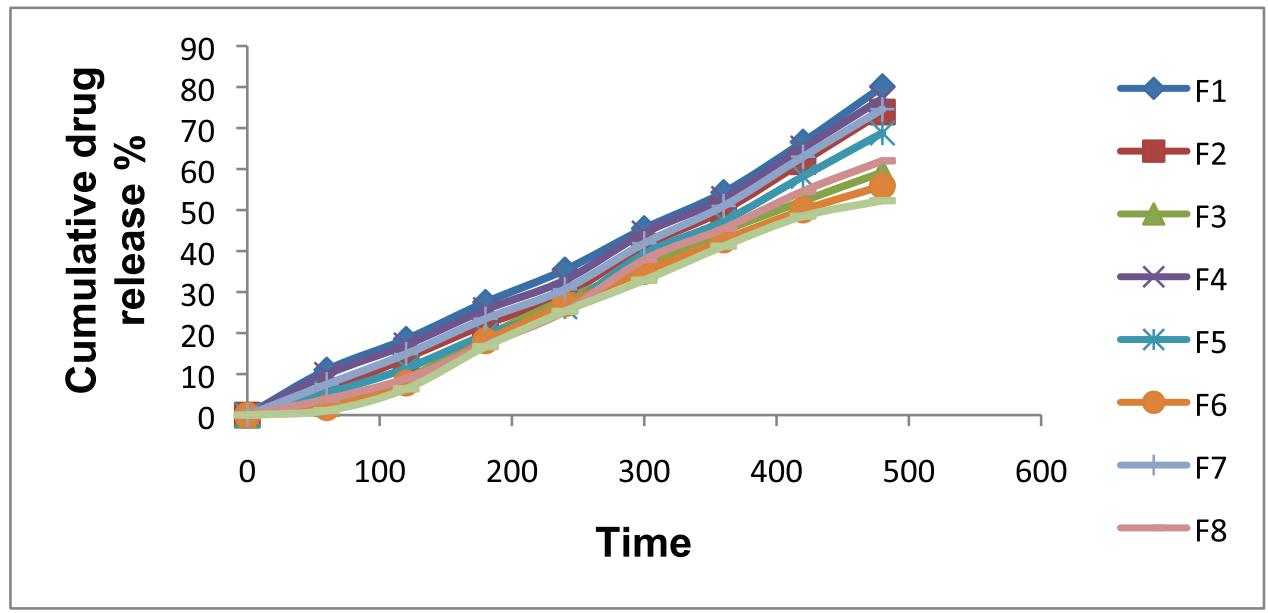

Figure 4. Metronidazole-carbopol 934P mucoadhesive microcapsules drug release.

Table 4. In vitro release kinetic models of metronidazole-carbopol 934P mucoadhesive microcapsules.

\begin{tabular}{cccccccccc}
\hline & \multicolumn{2}{c}{ Zero order } & \multicolumn{2}{c}{ First order } & & \multicolumn{2}{c}{ Higuchi } & \multicolumn{2}{c}{$\begin{array}{c}\text { Mechanism of drug } \\
\text { release }\end{array}$} \\
\hline & $\boldsymbol{R}^{\mathbf{2}}$ & $\boldsymbol{K}_{\mathbf{0}}$ & $\boldsymbol{R}^{\mathbf{2}}$ & $\boldsymbol{K}_{1}$ & $\boldsymbol{R}^{\mathbf{2}}$ & $\boldsymbol{K}\left(\mathbf{m i n}^{\mathbf{1} 2}\right)$ & $\boldsymbol{R}^{\mathbf{2}}$ & $\boldsymbol{n}$ \\
$\mathrm{F9}$ & 0.985 & 0.0 .121 & 0.977 & 0.00 & 0.858 & 2.674 & 0.0 .705 & 0.686 & Non-Fickian release \\
\hline
\end{tabular}




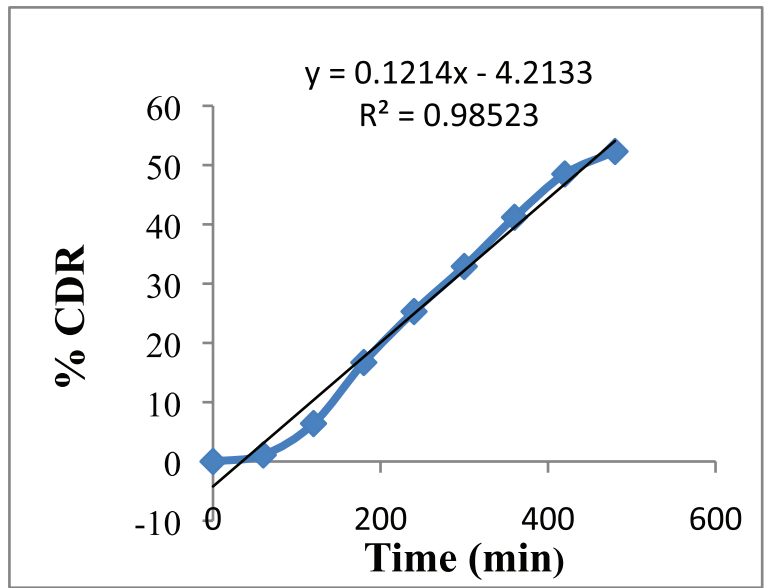

Figure 5. Zero-order release of F9.

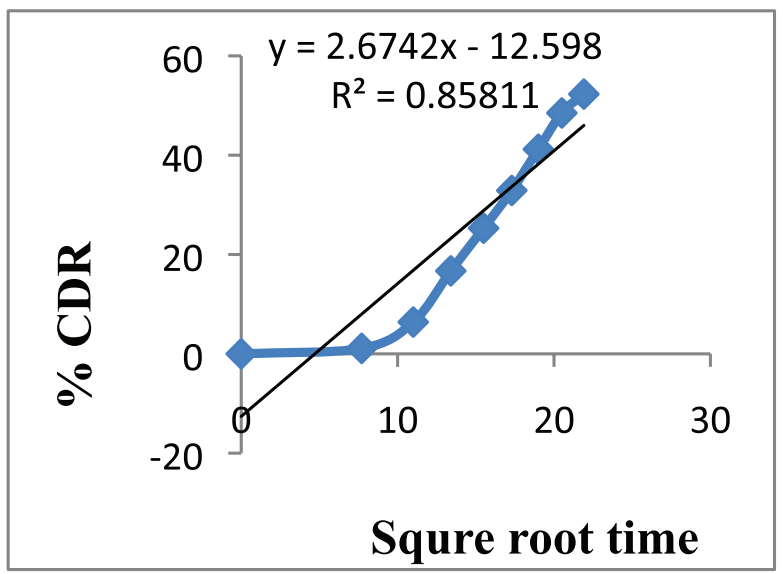

Figure 7. Higuchi model of F9.

synergistic effect, while a negative co-efficient indicates an antagonistic effect. Metronidazole microcapsules regression equation $(1,2,3$, and 4$)$ showed that positive sign $X_{1}$ (sodium alginate) and $X_{2}$ (carbopol 934P) illustrates the synergistic effect and indicates polymer concentration increase; the value of particle size, entrapment efficiency, SI, and mucoadhesion is also increased. On other hands, drug release was decreased when polymer concentration was increased. Equation was showed that if $X_{1}$ a had higher value of co-efficient compared with $X_{2}$ which indicated that $X_{1}$ had prominent effect $Y$. Oppositely, metronidazole microcapsules equation was shown that $X$ had a lower value of coefficient than $X_{2}$ which implies that $X_{2}$ had better effect $Y$. Negative effects of $X_{1}^{2}$ and $X_{2}^{2}$ suggest that as the total amount of polymer increases, entrapment efficacy increases slowly.

$$
\begin{array}{r}
Y=843.60+19.89 X_{1}+13.73 X_{2}-12.82 X-14.90 X_{1} X_{2} \\
\ldots \ldots \ldots \ldots . .(1) \\
Y=86.12+1.10 X_{1}+1.11 X_{2}-1.89 X_{1}^{2}-0.5633 X_{2}^{2} \\
-1.33 X_{1} X_{2} \ldots \ldots \ldots \ldots(2) \\
Y=96.07+3.54 X_{1}+4.17 X_{2}+0.8100 X_{1}^{2}-0.8850 X_{2}^{2} \\
-1.72 X_{1} X_{2} \ldots \ldots \ldots \ldots \ldots .(3)
\end{array}
$$

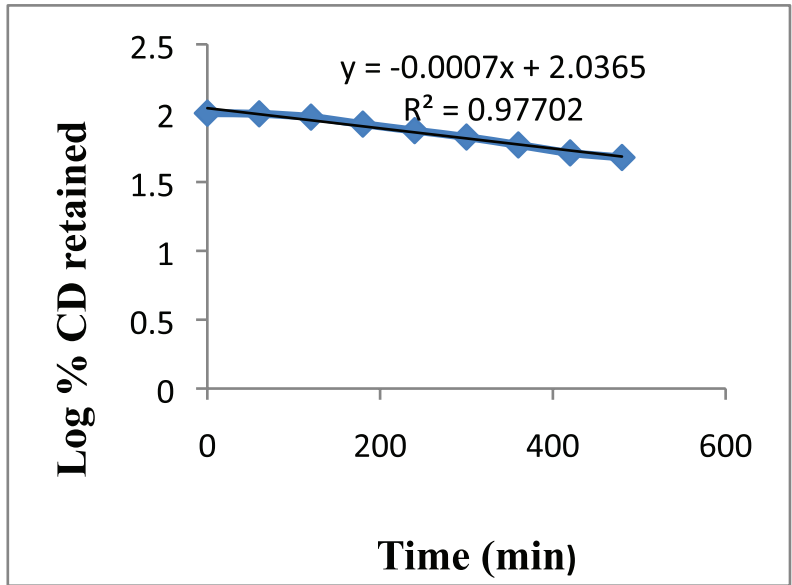

Figure 6. First-order release of F9.

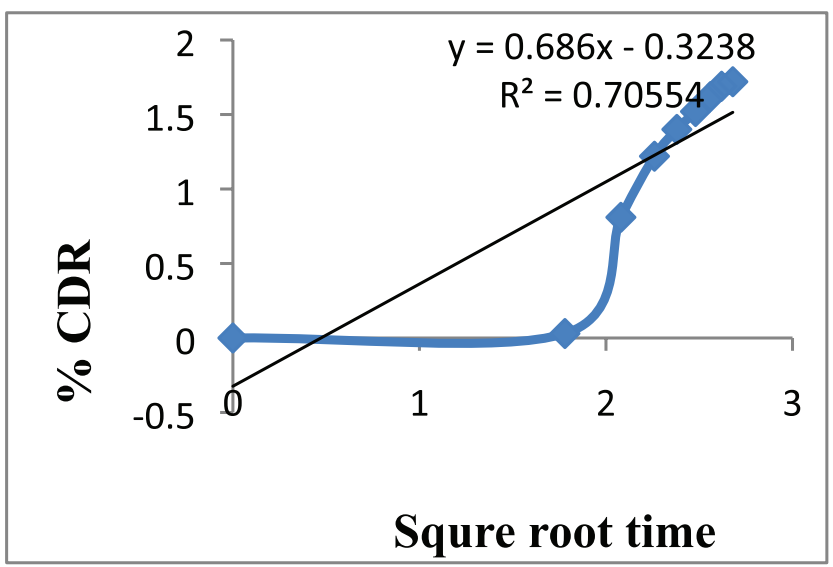

Figure 8. Korsmeyer-Peppas release of formulation F9.

$$
\begin{array}{r}
Y=59.33+5.17 X_{1}-0.5000 X_{2}-1.50 X_{1}^{2}-0.5000 X_{2}^{2} \\
-0.38 X_{1} X_{2} \ldots \ldots(4) \\
Y=68.42-4.05 X_{1}-10.75 X_{2}-0.2833 X_{1}-1.68 X_{2} \\
-0.3500 X_{1} X_{2} \ldots \ldots \ldots(5)
\end{array}
$$

Factorial design of ANOVA analysis, 3D response surface, and two-dimensional contour plots for metronidazole mucoadhesive microcapsules

ANOVA analysis was used to response combination formulations and it is also used to identify the formulations significant or insignificant. On other hands, three-dimensional response surface plots were generated for every response to study the performance of the manner and also assisted the main and interaction effects of the independent variables (factors), as well as a two-dimensional contour plot provides a visual representation of values of the response.

Table 5 shows sodium alginate and carbopol 934P value less than 0.0500 which are achieved statistically significant. Metronidazole mucoadhesive microcapsules were prepared using both polymers and the model was observed significantly. The contour plots (Figures 9A-13A) and response surface plots (Figures 9B-13B) indicated that the sodium alginate $\left(X_{1}\right)$ and carbopol 934P $\left(X_{2}\right)$ concentration was gradually increased, the 
Table 5. ANOVA analysis variance for the particle size, drug entrapment efficiency, SI, mucoadhesion, and drug release of metronidazole mucoadhesive microcapsules.

\begin{tabular}{|c|c|c|c|c|c|c|}
\hline Source & Sum of squares & df & Mean square & $F$ value & $p$-ValueProb $>$ F & Significant \\
\hline \multicolumn{7}{|c|}{ Particle size of metronidazole-carbopol 934P mucoadhesive microcapsules } \\
\hline Model & $4,380.83$ & 3 & $1,460.28$ & 14.96 & 0.0062 & Significant \\
\hline A-Sodium alginate & $2,360.17$ & 1 & $2,360.17$ & 24.18 & 0.0044 & Significant \\
\hline B-Carbopol 934P & $1,120.67$ & 1 & $1,120.67$ & 11.48 & 0.0195 & Significant \\
\hline \multicolumn{7}{|c|}{ Entrapment efficiency of metronidazole-carbopol 934P mucoadhesive microcapsules } \\
\hline Model & 32.41 & 5 & 6.48 & 17.37 & 0.0201 & Significant \\
\hline A-Sodium alginate & 12.30 & 1 & 12.30 & 32.95 & 0.0105 & Significant \\
\hline B-Carbopol 934P & 12.47 & 1 & 12.47 & 33.42 & 0.0103 & Significant \\
\hline \multicolumn{7}{|c|}{ Swelling index of metronidazole-carbopol 934P mucoadhesive microcapsules } \\
\hline Model & 191.17 & 3 & 63.72 & 43.47 & 0.0005 & Significant \\
\hline A-Sodium alginate & 75.05 & 1 & 75.05 & 51.20 & 0.0008 & Significant \\
\hline B-Carbopol 934P & 104.25 & 1 & 104.25 & 71.12 & 0.0004 & Significant \\
\hline \multicolumn{7}{|c|}{ Mucoadhesion of metronidazole-carbopol 934P mucoadhesive microcapsules } \\
\hline Model & 254.67 & 5 & 50.93 & 114.60 & 0.0013 & Significant \\
\hline A-Sodium alginate & 73.50 & 1 & 73.50 & 165.38 & 0.0010 & Significant \\
\hline B-Carbopol 934P & 160.17 & 1 & 160.17 & 360.38 & 0.0003 & Significant \\
\hline \multicolumn{7}{|c|}{ Drug release of metronidazole-carbopol 934P mucoadhesive microcapsules } \\
\hline Model & 0.0345 & 2 & 0.0173 & 98.44 & $<0.0001$ & Significant \\
\hline A-Sodium alginate & 0.0043 & 1 & 0.0043 & 24.62 & 0.0025 & Significant \\
\hline B-Carbopol 934P & 0.0302 & 1 & 0.0302 & 172.27 & $<0.0001$ & Significant \\
\hline
\end{tabular}

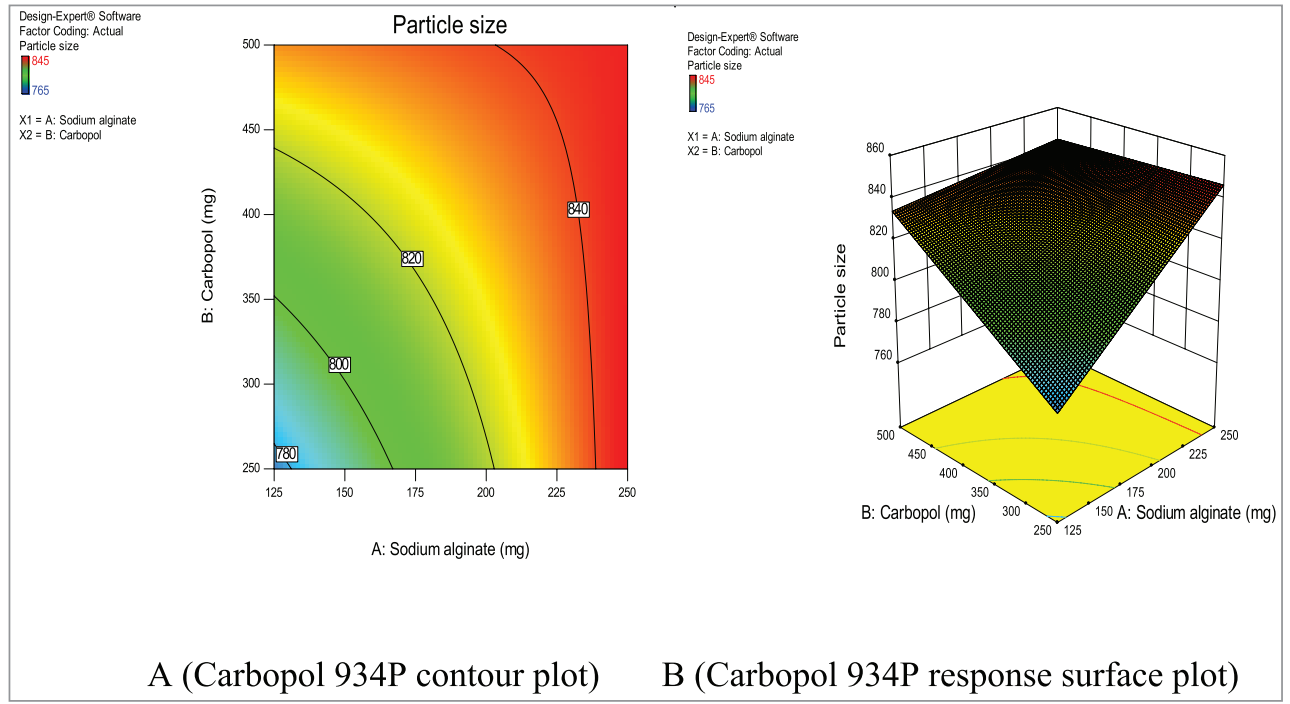

Figure 9. Metronidazole A (Contour plot) and B (Response plot) showing the effect of independent variables on the particle size of mucoadhesive microcapsules.

particle size was gradually increased, as well as sodium alginate $\left(X_{1}\right)$ and carbopol 934P $\left(X_{2}\right)$ concentrations were improved, drug release was also decreased.

\section{CONCLUSION}

The present investigation has successfully demonstrated the feasibility of ion gelation technique for the preparation of mucoadhesive microcapsules. The prepared microcapsules were found to be a successful alternative for sustaining the drug delivery and prolonging the residence time in the stomach, which is an obligation for complete eradication of upper GIT infection. A combination of carbopol 934P mucoadhesive microcapsules encapsulated with metronidazole drugs, respectively, have shown a satisfactory in-vitro sustained drug release $(52.30 \% \pm 0.01 \%$ in 14 hours, respectively) and mucoadhesive ability $(64.00 \% \pm 0.01 \%$, respectively) for 


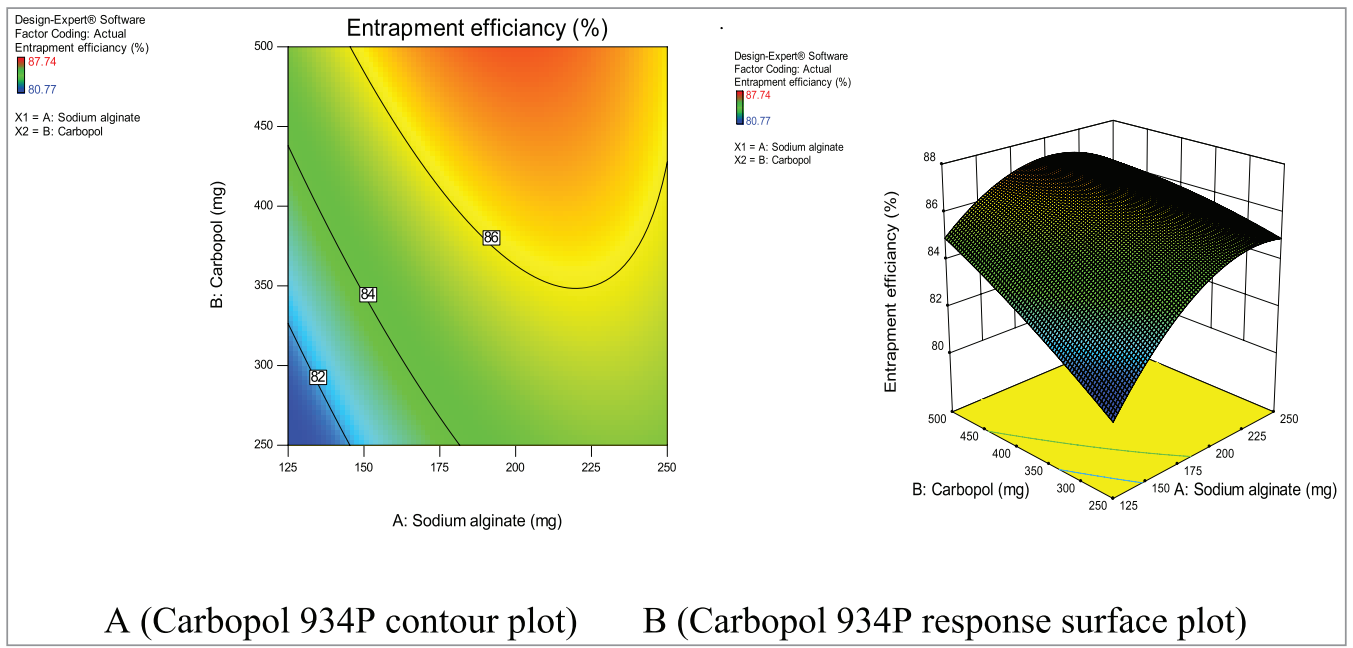

Figure 10. Metronidazole A (Contour plot) and B (Response plot) showing the effect of independent variables on the entrapment efficiency of mucoadhesive microcapsules.

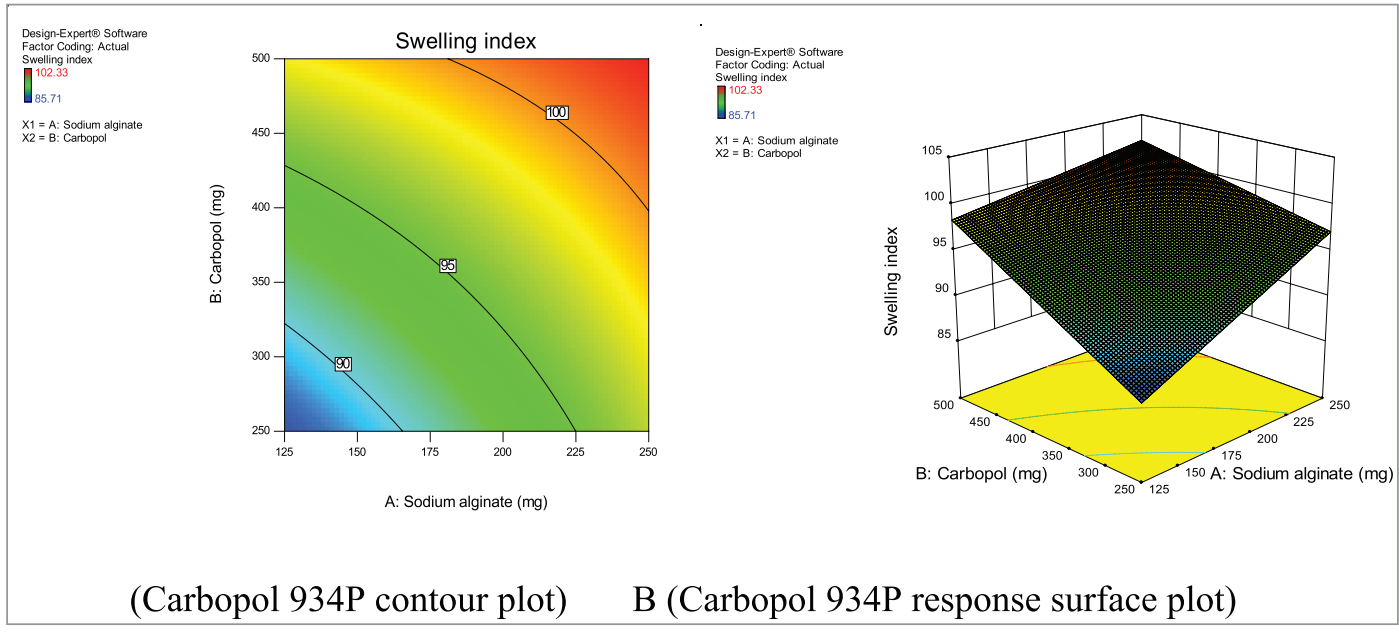

Figure 11. Metronidazole A (Contour plot) and B (Response plot) showing the effect of independent variables on the SI of mucoadhesive microcapsules.

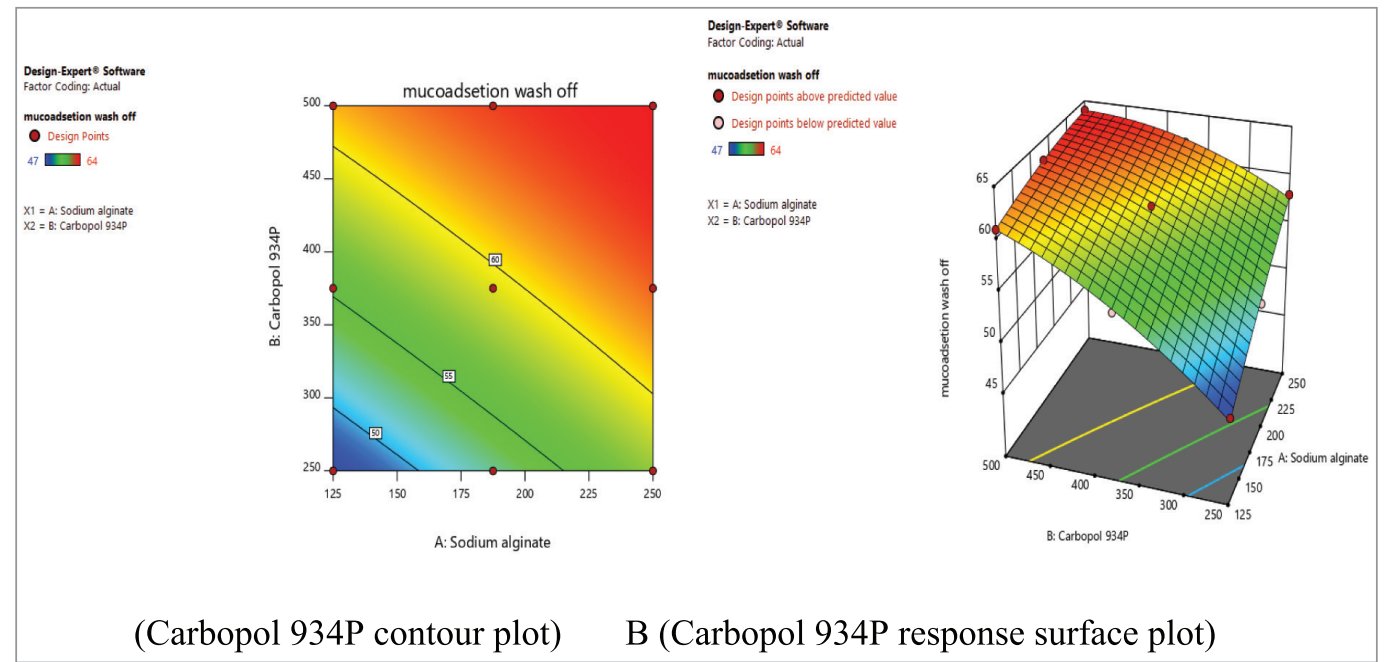

Figure 12. Metronidazole A (Contour plot) and B (Response plot) showing the effect of independent variables on the mucoadhesion of mucoadhesive microcapsules. 


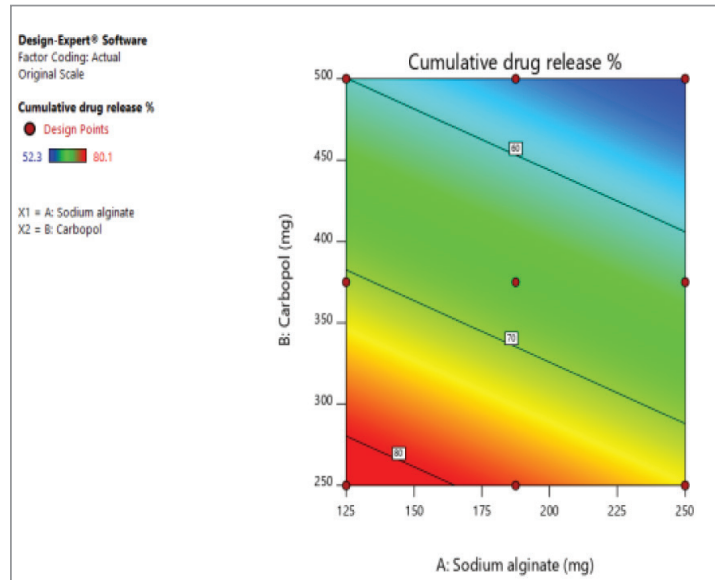

A (Carbopol 934P contour plot)

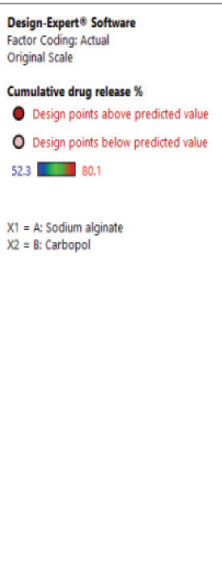

B (Carbopol 934P response surface plot)

Figure 13. Metronidazole A (Contour plot) and B (Response plot) showing the effect of independent variables on the drug release of mucoadhesive microcapsules.

prolonged residence time expected to eradicate the upper GIT infection. Additionally, the microencapsulated forms of metronidazole are also anticipated to have enhanced oral bioavailability, minimized harmful side effects, and reduced dosing frequency which would be further helpful to improve patient compliance. A non-Fickian controlled release mechanism of metronidazole mucoadhesive microcapsules. The results of $3^{2}$ factorial designs revealed that drug and polymer concentration significantly affected dependent variables entrapment efficiency, percentage release, particle size SI, mucoadhesion, and drug release. The metronidazole mucoadhesive microcapsules of the best formulation F9 exhibited high entrapment efficiency, the percentage of mucoadhesion, and sustain in gastric mucosa. Therefore, one can assume that metronidazole mucoadhesive microcapsules are promising pharmaceutical forms by providing controlled-release drug delivery systems.

\section{REFERENCES}

Abass HA, Kamel R. Formulation and evaluation of in situ forming polymeric drug delivery systems for mixed vaginal infection. British J Pharm Res, 2014; 4:2281-95.

Altafbhai MS, Vandana Y, Prasanth VV. Formulation and evaluation of mucoadhesive microspheres of metformin hydrochloride. Ind J Pharm Sci Res, 2014; 4:94-101.

Anuranjita K. Preparation and evaluation of sustained release microbeads of norfloxacin using sodium alginate. Int J Res Pharm Chem, 2012; 2:647-50.

Ardenia A, Gupta AK. Development and optimization of gastroretentive mucoadhesive microspheres using $3^{3}$ factorial design. Int J Pharm Sci Res, 2016; 7:2020-30.

Atishkumar SM, Pund YP. Design and development of sustained release floating beads of metronidazole using natural polymer. IOSR $\mathrm{J}$ Pharm, 2017; 1:1-9.

Arjun S, Ritika S, Faraz J. Sustained release drug delivery system: a review. Int Res J Pharm, 2012; 3:21-4.

Badhan AC, Mashru RC, Shah PP, Thakkar AR, Dobaria NB. Development and evaluation of sustained release gastroretentive minimatrices for effective treatment of $H$. pylori infection. AAPS Pharm Sci Tech, 2009; 10:459-67.

Badoni A, Ojha A, Gnanarajan G, Othiyal, P. Review on gastro retentive drug delivery system. Pharm Innov, 2012; 1(8):32-42.
Bhargava A, Rathore RPS, Tanwar YS, Gupta S, Bhaduka G. Oral sustained release dosage form: an opportunity to prolong the release of drug. Int J Adv Res Pharm Bio Sci, 2013; 3:7.

Bhatt K, Juyal D, Kala S, Mehra M. Oral sustained release drug delivery system: a concise review. W J Pharm Res, 2015; 4:871-82.

Carvalho FC, Bruschi ML, Evangelista RC, Gremiao MPD. Mucoadhesive drug delivery systems. Brazil J Pharm Sci, 2010; 46:1-17.

Chandra GI, Satyabrata B, Ellaiah P, Martha SK, Sahu PK, Tiwari SP, Panigrahi BB, Debajyoti D. Design and evaluation of acyclovir mucoadhesive microcapsules. Int J Pharm Sci Rev Res, 2010; 5:18-25.

Daemi H, Barikani M. Synthesis and characterization of calcium alginate nanoparticles, sodium homopolymannuronate salt and its calcium nanoparticles. Scientia Iranica, 2012; 19:2023-8.

Emara LH, Abdou AR, El-Ashmawy AA, Mursi NM. Preparation and evaluation of metronidazole sustained release floating tablets. Int J Pharm Pharm Sci, 2014; 6:199-204.

Garud A, Garud N. Preparation and evaluation of chitosan microcapsules of metronidazole using tripolyphosphate cross-linking method. Dhaka Univ J Pharm Sci, 2010; 9:125-30.

Hosmani AH, Kasture PV, Gonjari ID, Karmarkar AB. Study of formulation variables on properties of glipizide mucoadhesive microspheres by factorial design. DARU, 2009; 17:236-42.

Jain SK, Nitin KJ, Gupta Y, Jain A, Jain D, Chaurasia M. Mucoadhesive chitosan microspheres for non-invasive and improved nasal delivery of insulin. Ind J Pharm Sci, 2007; 69:498-504.

Jiménez MRC, Zia H, Rhodes CT. Design and testing in vitro of a bioadhesive and floating drug delivery system for oral application. Int $\mathrm{J}$ Pharm, 1994; 105:65-70.

Kalita B, Saikia K, Kalita B. Formulation and evaluation of metronidazole microspheres-loaded bioadhesive vaginal gel. Asian J Pharm Clin Res, 2017; 10(3):418-24.

Kumar SH, Sunita L, Lila KN. Formulation and in vitro evaluation of metformin hydrochloride loaded microspheres prepared with polysaccharide extracted from natural sources. Acta Pharm, 2013; 63:209-22.

Kube RS, Kadam VS, Shendarkar GR, Jadhav SB, Bharkad VB. Sustained release drug delivery system: review. Ind J Res Pharm Biotechnol, 2015; 3:246-51.

Kumar MP, Ishaq BM, Reddy RK, Kumar RP, Badrinath AC, Chetty CM. Formulation and evaluation of colon specific matrix and coated tablet of metronidazole. Int Res J Pharm, 2011; 2:194-9.

Mazumder R, Nath LK, Haque A, Maity T, Choudhury PK, Bhrestha B, Chakraborty M, Pal NR. Formulation and in vitro evaluation of 
natural polymers based microspheres for colonic drug delivery. Int J Pharm Pharm Sci, 2010; 2:211-9.

Nagda CD, Chotai NP, Patel SB, Soni TJ, Patel ULN. Preparation and in vitro evaluation of bioadhesive microparticulate systems. Int J Pharm Sci Nanotechnol, 2008; 1:266-75.

Nayak AK, Pal D, Pradhan J, Hasnani MS. Fenugreek seed mucilage-alginate composite beads of metformin $\mathrm{HCl}$ : design, optimization and evaluation. Int J Bio Macromole, 2013; 54:144-54.

Nimisha BM, Bhattacharya A. Formulation and evaluation of bioadhesive microcapsules of tizanidine hydrochloride for nasal drug delivery. Ind Pharma, 2008; 7:71-7.

Nnabuike DN, Tochukwu JNO. Optimization of metronidazole tablet formulation using Manihotutilissima starch and a combination of processing techniques. Future J Pharm Sci, 2017; 3:65-70.

Pal D, Nayak AK. Development, optimization, and anti-diabetic activity of gliclazide-loaded alginate-methyl cellulose mucoadhesive microcapsules. AAPS PharmSciTech, 2011; 12:1431-41.

Rajesh M, Jaifar P, Helen SA, Asha C, Palanichamy S, Thanga TA. Formulation and evaluation of mucoadhesive microcapsules of aceclofenac. J Pharm Res, 2012; 5:1428-31.

Reddy KVR, Nagabhushanam MV, Naik ER. Effect of drying techniques on drug release of cross linked alginate simvastatin beads by using hydrophilic polymers. Res J Pharm Bio Che Sci, 2017; 8:2015-29.

Rizwana K. Gastroretentive drug delivery system - a review. Int J Pharma Bio Sci 2013; 4(2):630-46.

Satinder K, Shashi K, Bharat P. Sustained release drug delivery system: a review. Int J Institut Pharm L Sci, 2012; 2:356-76.

Sathali AH, Varun J. Formulation, development and in vitro evaluation of candesartan cilexetil mucoadhesive microbeads. Int J Curr Pharm Res, 2012; 4:109-18.

Shastri DH, Dodiya HD, Shelat P, Bhanupriy AK. Formulation development and evaluation of a gastroretentivein situ oral gel of cefuroxime axetil. J Young Pharma, 2016; 8:324-9.

Shankar, Hardenia S, Jain A, Ritesh P, Anu KA. Formulation and evaluation of mucoadhesive microspheres of ciprofloxacin. J Adv Pharm Educ Res, 2011; 1:214-24.

Shanthi PCH. Design and characterization of mucoadhesive microspheres for gastro-retentive delivery of famotidine hydrochloride. J Bioeng Biomel Sci, 2015; 5:2-6.
Shivangi S, Nithya S, Mahato AK. 2016, Formulation and evaluation of metronidazole tableted microspheres for colon drug delivery. Asian J Pharm Clin Res, 2016; 9:398-403.

Shwetha S., Kamath K, Senthil Kumar SK. Design and evaluation of floating microspheres of Rabeprazole sodium. Int J Pharm Pharm Sci, 2012; 4:357-67.

Sriram N, Katakam P. Formulation and evaluation of mucoadhesive microspheres of pioglitazone hydrochloride prepared by ionotropic external gelation technique. J Encapsula Adsorp Sci, 2016; 6:22-34.

Stephen RB, Rajveer CH, Sudharshini S, Kishore RA. Preparation and evaluation of mucoadhesive microcapsules of Nimodipine. Int J Res Pharm, 2010; 1:219-24.

Swetha K, Vani V, Satyabrata B, Sudhakar M. Formulation and evaluation of mucoadhesive micropsheres of Irbesartan. J Adv Pharm Educ Res, 2013; 3:450-63.

Subhashree S, Chandra KC, Pradipta KB. Characterization of controlled release ofloxacin suspensions by Fourier transform infrared spectroscopy. Res J Pharm Biolog Cheml Sci, 2011; 2:926-39.

Uttam KM, Bappaditya C, Faria GS. Gastro-retentive drug delivery systems and their in vivo success: A recent update. Asian J Pharm Sci 2016; 11:575-84.

Yadav AV, Shete AS, Dabake AP, Shinde VR. Formulation and in vitro evaluation of Aceclofenac microcapsules. Int J PharmTech Res, 2009; $1: 135-8$.

How to cite this article:

PaulB,AdimoolamS, QureshiMJ.Developmentandevaluation of metronidazole loaded carbopol 934P mucoadhesive microcapsules for sustained drug release at the gastric mucosa. J App Pharm Sci, 2018; 8(12): 020-031. 